\title{
O REGIME DE METAS DE INFLAÇÃO NO BRASIL: UMA ANÁLISE EMPÍRICA DO IPCA*
}

\author{
Aniela Fagundes Carrara ${ }^{a}$ \\ André Luiz Correa ${ }^{b}$
}

RESUMO: O regime monetário de metas de inflação é um padrão de conduta da política monetária que passou a ser utilizado por vários países a partir da década de 1990, dentre eles o Brasil, que adotou este modelo em 1999, após uma crise cambial. Com seu arcabouço teórico pautado nas premissas da teoria novo-clássica e tendo como principal característica o anúncio prévio de uma meta numérica para a inflação, este regime passou a ser adotado por países que buscavam alcançar a estabilidade de seus preços. O presente trabalho irá brevemente expor a base teórica e as características do referido regime. Porém, o foco principal será a discussão da utilização do IPCA (Índice de Preços ao Consumidor Amplo) pelo regime de metas como balizador da inflação no Brasil.

PALAVRAS-CHAVE: Metas de inflação; política monetária; índices de preço.

CLASSIFICAÇÃO JEL: E52; E43; E47.

\footnotetext{
*Artigo recebido em 29/08/2011 e aprovado em 29/11/2012.

a Mestranda em Economia Aplicada do Programa de Pós-Graduação em Economia Aplicada da Escola Superior de Agricultura Luiz de Queiroz da Universidade de São Paulo (ESALQ-USP). Contato: anielacarrara@ig.com.br.

${ }^{\mathrm{b}}$ Doutor em Economia pela Universidade Estadual de Campinas (UNICAMP) e professor assistente do Departamento de Economia da Universidade Estadual Paulista Júlio de Mesquita Filho (UNESP) - campus Araraquara. Contato: andrelc@fclar.unesp.br.
} 


\section{INFLATION TARGETING IN BRAZIL: AN EMPIRICAL ANALYSIS OF IPCA}

ABSTRACT: Inflation targeting regime is a monetary policy adopted by several countries in the 1990s, Brazil being among them, which adopted it in 1999 after a currency crisis. With a theoretical framework inspired by the new-classical theory, this regime is adopted by countries attempting to achieve price stability and it brings the prior announcement of a numerical target for inflation as a key feature. The present work aims at discussing the use of IPCA (Consumer Price Index) as a measuring index for Brazil's inflation after briefly explain the theoretical basis of the IT regime.

KEYWORDS: Inflation targeting; monetary policy; price indexes. 


\section{INTRODUÇÃO}

Durante a década de 1990, o regime de metas de inflação tornou-se um instrumento utilizado por vários países que procuravam institucionalizar a busca da estabilidade de seus preços, dar maior transparência à condução da política monetária, eliminar os problemas ligados ao viés inflacionário e, por conseguinte, fazer com que a sua autoridade monetária tenha maior credibilidade.

Essa forma de conduzir a política econômica é pautada no arcabouço teórico da escola novo-clássica, que trabalha com hipóteses tais como as expectativas racionais e equilíbrio contínuo dos mercados, além de defender proposições como a ineficácia e a inconsistência temporal da política monetária e argumentar a favor da tese de independência do Banco Central. Aliás, foi a partir de um desdobramento desta tese que surgiu a proposta das metas inflacionárias.

Os pontos gerais desse regime monetário consistem na publicação periódica de metas numéricas para a inflação, bem como de determinados intervalos para sua variação, e de um espaço de tempo para que se possa alcançá-las, visando, deste modo, ao conhecimento por parte do público das metas numéricas, à transparência das ações dos formuladores de política, e ao comprometimento com a estabilidade de preços e com o cumprimento das metas.

No cenário econômico brasileiro, o regime de metas de inflação foi implementado de acordo com as características macroeconômicas do país quando da implementação em meados de 1999, no que diz respeito à escolha das metas, dos intervalos de variação e do índice que mediria a inflação. Esse processo e os debates que foram surgindo ao longo do mesmo serão expostos por esse trabalho, que apresentará em sua última seção uma explicação teórica e empírica mais detalhada de um dos motivos de grande discussão entre os proponentes do regime de metas inflacionárias e seus críticos, que é a escolha do Índice de Preços ao Consumidor Amplo (IPCA) como balizador da inflação.

\section{ARCABOUÇO TEÓRICO DO REGIME DE METAS DE INFLAÇÃO}

A escola de pensamento novo-clássica consolidou-se durante a década de 1970, quando inúmeras críticas abalaram o consenso keynesiano que havia predominado na macroeconomia durante as décadas de 1950 e 1960. Robert Lucas, Thomas Sargent e Neil Wallace foram os precursores dessas críticas e de algumas novas hipóteses introduzidas pela referida escola, destacando-se a aversão às ideias dos keynesianos de intervenção macroeconômica e a não concordância com a caracterização dos instrumentos utilizados pelos agentes para formarem suas expectativas, postulada por Friedman. Ou seja, os novo-clássicos rejeitavam a ideia das expectativas adaptativas, tanto que no 
seu lugar propuseram a hipótese das expectativas racionais. Por outro lado, incorporaram dois elementos cruciais do monetarismo: a hipótese da existência de uma taxa natural de desemprego e a concepção monetarista de que a inflação é um fenômeno essencialmente monetário.

Esta escola de pensamento trouxe algumas implicações que foram importantes para seus desenvolvimentos futuros, tais como:

i) A ineficácia da política monetária. A hipótese da existência de uma taxa natural de desemprego é o ponto inicial para essa construção. Sendo os agentes racionais, qualquer regra de política monetária seria incorporada por eles às suas expectativas; assim, a referida política tornar-se-ia incapaz de afetar as variáveis reais, ou seja, partindo-se de uma situação na qual a taxa corrente de desemprego é igual à taxa natural, quando o governo anuncia, por exemplo, uma elevação na oferta de moeda, os agentes vão reagir a essa decisão apenas aumentando seus preços, sem ofertar nenhuma vaga adicional de trabalho e, conforme dito acima, nenhuma variável real será afetada, já que a taxa corrente de desemprego permanecerá igual à taxa natural. Restará para as autoridades monetárias somente o elemento surpresa dos agentes, isto é, quando são introduzidas novas variáveis no mundo real, ou quando se altera inesperadamente a magnitude de variáveis já existentes como forma de afetar o nível de emprego (e de renda), ainda que essa alteração ocorrerá somente a curto prazo até que os agentes incorporem o novo elemento às suas expectativas. Este é um dos resultados mais controversos dessa teoria macroeconômica, já que reduz a eficácia da política monetária à criação de surpresas.

(ii) A inconsistência temporal da política monetária e o viés inflacionário. Este problema foi inicialmente estudado por Kydland e Prescott (1977) e posteriormente aprofundado por Calvo (1978) e Barro e Gordon (1983). Entende-se por ele o fato de a autoridade monetária participar de um jogo dinâmico com os agentes racionais privados no qual atua como uma espécie de líder e anuncia uma taxa de crescimento do estoque monetário, cabendo aos agentes formarem suas expectativas com base no que foi anunciado dependendo do fator credibilidade. Depois das expectativas formuladas, resta à autoridade monetária duas opções: cumprir ou não cumprir (trair) o que foi divulgado. Quando a política monetária é conduzida discricionariamente, ou seja, a autoridade monetária é incentivada a trair e não adotar os parâmetros de política monetária previamente anunciados, há um viés inflacionário. Os agentes racionais, por sua vez, reconhecem a existência desse viés inflacionário na condução (discricionária) da política econômica, e isso compromete a credibilidade da referida política. É justamente este último resultado do modelo novo-clássico que traz à tona a argumentação a favor da adoção de regras de política monetária, que, por sua vez, é o embrião para o regime de metas de inflação: "As implicações para nossa análise é que os policymakers devem seguir regras definidas ao invés de atuarem discricionariamente" (Kydland e Prescott, 1977, p. 487). 
E foi a partir dos resultados explicitados acima, principalmente o último, que se deu origem à tese da independência do Banco Central (IBC), que, posteriormente, serviu de fundamento para a criação da política de metas para a inflação. Esta tese pressupõe a existência de um viés inflacionário na condução da política monetária e de uma correlação negativa entre o grau de independência do Banco Central e a inflação. Isso vem ao encontro da ideia de se criar uma tecnologia de comprometimento com base em arranjos institucionais, de modo a limitar a discricionariedade da autoridade monetária, proposta por Kydland e Prescott (1977). Esta tese é mais uma solução apontada pelos teóricos para o problema da inconsistência temporal da política monetária. Dentre os inúmeros trabalhos sobre o referido assunto, se destacam os de Alex Cukierman (1994), Charles Goodhart (1993), Rogoff (1985) e Walsh (1995).

A tese da IBC tem como base de seu desenvolvimento o trinômio credibilidade-reputação-transparência, estabelecido por alguns estudiosos da teoria novo-clássica, e encontrou grande respaldo em países desenvolvidos. A proposta das metas inflacionárias, por sua vez, surgiu como um desdobramento da tese da IBC, e sua motivação inicial se encontra na formulação do problema da inconsistência temporal, originalmente realizada por Kydland e Prescott (1977).

O regime de metas inflacionárias pode ser definido como uma estratégia de condução da política monetária baseada no anúncio de uma meta para a inflação no início de determinado período que é estabelecida pelo governo e/ou parlamento e deve ser perseguida pelo Banco Central. Este regime visa a uma maior transparência na condução da política monetária baseada na busca pelo aprimoramento dos canais de comunicação entre o Banco Central e os agentes econômicos para que possa haver um monitoramento e uma avaliação do desempenho da autoridade monetária, sempre supondo a aceitação da neutralidade da moeda. Desta forma, essas metas podem coordenar a formação de expectativas inflacionárias dos agentes e a fixação de salários e preços, atuando, assim, como uma âncora nominal tanto para a inflação atual como para as expectativas futuras.

\section{O REGIME DE METAS INFLACIONÁRIAS NO BRASIL}

O regime monetário de metas de inflação foi implantado no Brasil em um cenário de fortes desvalorizações decorrentes de ataques especulativos, fruto dos desdobramentos da política econômica do Plano Real, que procurou combater o alto processo inflacionário vivido pela economia brasileira a partir de uma política de estabilização da moeda nacional e da liberalização econômica.

O referido regime foi formalmente adotado no dia $1^{\circ}$ de julho de 1999 através do Decreto Presidencial n 3.088 , de 21 de junho de 1999, que, dentre outras coisas, tinha como principais pontos: (i) fixar as metas para a inflação com base em variações anuais 
de um índice de preços conhecido; (ii) deixar a cargo do Conselho Monetário Nacional $(\mathrm{CMN})^{1}$ a determinação das metas para a inflação (mediante proposta do ministro da Fazenda), seus respectivos intervalos de variação e o índice de preços a ser cotado; (iii) incumbir ao Banco Central a tarefa de fazer com que as metas estabelecidas fossem cumpridas, utilizando para isso os instrumentos necessários. A meta será considerada cumprida quando a inflação acumulada no ano, medida pelo índice de preços escolhido pelo CMN, se encontrar dentro da faixa de tolerância preestabelecida. Em caso de descumprimento das metas, o presidente do Banco Central deverá escrever uma carta aberta ao ministro da Fazenda explicando as razões do não cumprimento e as medidas a serem tomadas para fazer a inflação voltar para dentro do intervalo estabelecido, bem como o prazo para isso acontecer.

E, por fim, visando à transparência da política utilizada e dos resultados alcançados, criar-se-ia uma publicação trimestral com o nome de Relatório Trimestral de Inflação, que apresentaria, segundo Modenesi (2005): i) os objetivos, as limitações e as medidas de política monetária tomadas pelo Banco Central; ii) os resultados de medidas futuras; e iii) a avaliação prospectiva do comportamento da inflação, visto o caráter de antecipação das decisões do Banco Central, devido à existência de defasagens na condução da política monetária.

Pela Resolução 2.615, de 30 de junho de 1999, ficou determinado pelo CMN que o índice a ser utilizado como referência para o regime de metas de inflação seria o Índice de Preços ao Consumidor Amplo (IPCA), calculado pelo Instituto Brasileiro de Geografia Estatística (IBGE) desde dezembro de 1979 (características deste índice serão apresentadas no item 4). Nesta mesma resolução, também foram anunciadas as metas de $8 \%, 6 \%, 4 \%$ para os anos de 1999, 2000 e 2001, respectivamente.

É importante fazer-se notar que as autoridades monetárias brasileiras não seguiram alguns países, como o Canadá, Nova Zelândia, Austrália, Holanda e Suécia, que adotaram como parâmetro alguma medida do núcleo da inflação, que acaba por isolar o efeito de choques temporários sobre a inflação. Núcleo da inflação é uma forma de calcular a inflação que exclui ou confere menor importância aos aumentos provocados por fatores temporários ou casuais na composição do índice de preços. Essa técnica de cálculo é utilizada para que se tenha o real comportamento da inflação considerando aí as variações que sejam consistentes com o comportamento de toda a economia, e não apenas os fatores localizados. Sendo assim, um aumento generalizado de preços na economia aparece no núcleo,

\footnotetext{
${ }^{1}$ O Conselho Monetário Nacional (CMN) é o órgão deliberativo máximo do Sistema Financeiro Nacional. Ao CMN compete: estabelecer as diretrizes gerais das políticas monetária, cambial e creditícia; regular as condições de constituição, funcionamento e fiscalização das instituições financeiras; e disciplinar os instrumentos de políticas monetária e cambial. O CMN é constituído pelo ministro de Estado da Fazenda (presidente), pelo ministro de Estado do Planejamento e Orçamento, e pelo presidente do Banco Central do Brasil (Bacen). Os serviços de secretaria do CMN são exercidos pelo Bacen. Fonte: <http://www.fazenda.gov.br/ portugues/orgaos/cmn/cmn.asp >.
} 
mas um aumento localizado no preço de algum item de consumo por conta de qualquer evento exógeno é excluído.

Utilizar-se da metodologia do núcleo da inflação acaba por isolar o efeito de choques temporários sobre a mesma, o que é preferível do ponto de vista técnico, como aponta de maneira mais detalhada Farhi (2004):

Bancos Centrais de diversos países desenvolvidos que utilizam um regime de metas de inflação ou não procuram neutralizar os efeitos dos choques exógenos sobre suas políticas monetárias de forma que essas não sejam contaminadas por fatores sobre os quais as taxas de juros só terão efeito se provocarem uma acentuada queda de demanda. Valem-se, para isso, de um parâmetro de inflação medido pelo método conhecido como "núcleo da inflação", que reduz o impacto de choques de oferta ou os advindos da variação cambial. Se um núcleo da inflação fosse empregado no Brasil como parâmetro para o regime de metas, a política monetária seria menos suscetível a choques externos e não precisaria ser tão apertada. (Farhi, 2004, p. 82)

Porém, essa metodologia pode gerar perda de credibilidade, uma vez que os critérios para a definição do núcleo da inflação podem não ser facilmente compreensíveis para os agentes. Sendo assim, a decisão de não adotar nenhum núcleo da inflação foi seguida para não comprometer a credibilidade das metas e de seus resultados logo no período de implementação:

Esta postura se justifica pela tentativa de fornecer maior credibilidade ao regime. Posto que, por um lado, existe uma grande desconfiança e incompreensão sobre a utilização de expurgos de itens considerados mais voláteis, o que é compreensível em virtude das tentativas realizadas no Brasil, há não muito tempo, de mascarar os verdadeiros resultados inflacionários. Por outro lado, a adoção de novos recursos poderia ser interpretada pelos agentes econômicos como mudanças nas regras, o que poderia levar à perda de credibilidade. (Ferreira, 2004, p. 79)

De acordo com o decreto que instituiu o regime monetário de metas de inflação, ficou a cargo do Banco Central assegurar o cumprimento da meta estipulada para a taxa de variação do IPCA, mais especificamente a cargo do Comitê de Política Monetária do Banco Central (COPOM), que já existia desde 20 de junho de 1996 mas que, depois da instituição do novo regime, passou a objetivar a implementação das metas para a inflação. O instrumento de política monetária escolhido pelo COPOM para controlar o nível de preços foi a taxa de juros SELIC.

A SELIC é a taxa que serve de referência para os juros da economia brasileira, que baliza as trocas de reservas entre as instituições financeiras e é considerada pelo mercado como o principal indicador de política monetária do governo. Esta taxa custodia todos os títulos de emissão do Banco Central do Brasil, do Tesouro Nacional, dos estados e dos municípios, bem como os depósitos interfinanceiros, custodiados pelos bancos múltiplos com carteira comercial, bancos comerciais e caixas econômicas (Carvalho et al,. 2007). 
Para manter a SELIC em conformidade com a meta mensal estipulada pelo COPOM, o Banco Central gerencia a liquidez do sistema econômico de tal forma que, se for necessário, ele pode atuar por meio de suas operações fazendo com que o mercado fique com escassez de reservas, "obrigando", assim, os bancos a tomarem seus empréstimos rotineiros junto a ele a uma taxa de juros mais elevada, o que acabará por torná-la efetiva, já que os bancos também vão repassar essa alta para seus clientes.

\section{O USO DO IPCA COMO REFERÊNCIA PARA A INFLAÇÃO}

No Brasil, o IPCA, calculado pelo IBGE, foi escolhido pelo Banco Central para acompanhar os objetivos estabelecidos no sistema de metas de inflação. Seu cenário de pesquisa é composto por famílias que ganham de um a 40 salários mínimos, seja qual for a fonte de seus rendimentos. E seus dados são coletados nas áreas urbanas das regiões metropolitanas do Rio de Janeiro, Porto Alegre, Belo Horizonte, Recife, São Paulo, Belém, Fortaleza, Salvador e Curitiba, além do Distrito Federal e do município de Goiânia.

O IPCA é um tipo de índice de Laspeyres que calcula a mudança dos preços de bens e serviços entre dois períodos (comparação dos preços que vigoraram nos 30 dias do período de referência com os 30 dias do período-base) ponderando a participação das despesas com cada bem no consumo total. Os tipos de gastos que compõem a estrutura do IPCA são os seguintes: gastos com alimentação, transporte e comunicação, despesas pessoais, vestuário, habitação, saúde e cuidados pessoais, e artigos de residência.

No conjunto das diferentes despesas discriminadas acima, a precificação pode ser feita através de dois tipos de preços: (i) os preços livres, que são determinados pelas forças de oferta e de demanda existentes na economia; e (ii) os preços administrados, que são muito pouco, ou nada, influenciados pelas forças de oferta e de demanda. A conceituação do Banco Central do Brasil em relação a esse tipo de preço, que foi extraída do Banco Central do Brasil (dez. 2002), é a seguinte:

Entende-se por preços administrados por contrato ou monitorados (doravante, preços administrados) aqueles preços cuja sensibilidade a fatores de oferta e demanda é menor, mas não necessariamente aqueles que são diretamente regulados pelo governo. Também são considerados preços administrados aqueles que, a despeito de estarem relacionados com oferta e demanda, dependem de autorização ou conhecimento prévio de algum órgão do poder público. (Banco Central do Brasil, 2002, p. 125-128)

Os preços administrados por contrato ou monitorados são divididos em dois grupos: os que são regulados em nível federal e os que são regulados em níveis estadual e municipal. No que se refere à determinação dos preços administrados, a periodicidade 
e a magnitude dos reajustes são discricionárias, variando de acordo com as respectivas autoridades reguladoras. $\mathrm{O}$ ponto fundamental é que a inflação passada tem papel fundamental na determinação desses reajustes.

Segundo o Banco Central, atualmente são 28 o número de bens e serviços da cesta do IPCA classificados como preços administrados, totalizando 29,5\% deste índice (em março de 2010). De acordo com o Banco Central, dentro desses preços, o maior peso por subcategoria é o dos produtos derivados de petróleo $(5,51 \%)$, seguido por transporte $(5,22 \%)$, serviços telefônicos $(4,86 \%)$, planos de saúde $(3,43 \%)$, energia elétrica residencial $(3,23 \%)$, e produtos farmacêuticos $(2,81 \%)$. Esses seis grupos somam $84,96 \%$ do peso dos preços administrados no IPCA, ou 25,06\% do índice.

Analisando o período de janeiro de 1995 a março de 2010, fica claro que a variação dos preços monitorados por contrato $(417,4 \%)$ foi maior do que a variação do IPCA (203\%) e dos preços livres (166,5\%). Como é mostrado a seguir:

Tabela 1 - Evolução dos principais preços administrados entre jan./1995 e mar./2010 (em \%)

\begin{tabular}{c|c|c|c|c}
\hline Itens & $\mathbf{1 9 9 5 - 1 9 9 8}$ & Jan/1999-Mar/2010 & Jan/1995-Mar/2010 & Jan/2007-Mar/2010 \\
\hline IPCA & 43,5 & 111,2 & 203 & 17,8 \\
\hline Preços administrados & 88,2 & 174,8 & 417,4 & 11,2 \\
\hline Tarifas de telefonia fixa & 309,7 & 126 & 825,8 & 5 \\
\hline Gás de cozinha & 121,2 & 320,1 & 829,5 & 18 \\
\hline Eletricidade & 89,6 & 173,7 & 419 & $-0,6$ \\
\hline Ônibus urbano & 97,8 & 195,4 & 484,3 & 21,8 \\
\hline Gasolina & 51,5 & 211,8 & 372,4 & 1,4 \\
\hline Tarifas de água e esgoto & 84,5 & 181 & 418,4 & 24,1 \\
\hline Seguro de saúde & 126,6 & 142 & 448,4 & 20,8 \\
\hline Preços livres & 37 & 94,5 & 166,5 & \\
\hline
\end{tabular}

Fonte: Banco Central do Brasil (2010, p. 10).

Agora que já foi mostrado um pouco da formação e da trajetória do IPCA e de seus componentes dentro do regime de metas de inflação, o próximo passo será a realização de uma analise empírica do referido índice com o intuito de avaliar se realmente ele é uma boa medida para a inflação brasileira, na qual será testado o seu comportamento perante variações ou choques que afetam o cenário econômico do país. Porém, antes de apresentar e discutir os resultados, fazem-se necessárias algumas explicações sobre os procedimentos econométricos e as variáveis utilizadas no presente estudo.

\section{PROCEDIMENTOS ECONOMÉTRICOS}

Com vistas a contemplar o objetivo proposto de analisar se o IPCA realmente é uma boa referência para as metas de inflação, iremos utilizar procedimentos de séries temporais. Antes de se estimar as relações entre as variáveis, é necessário 
avaliar as propriedades estatísticas das séries que serão utilizadas iniciando pelos testes de estacionariedade.

Basicamente uma série temporal é dita estacionária quando a mesma consegue dissipar ao longo do tempo o efeito de um choque qualquer no valor de suas variáveis, retornando, dessa forma, para seu valor histórico e mantendo sua média, variância e autocovariância estáveis independentemente do período de tempo em que sejam medidas. Umas das formas mais utilizadas de se verificar a estacionariedade de uma série temporal é por meio da utilização dos testes de raiz unitária, já que uma série não estacionária possui pelo menos uma raiz unitária. O teste de raiz unitária a ser utilizado neste trabalho será o teste aumentado de Dickey-Fuller (ADF), como é sugerido por Enders (2004).

Após testar a estacionariedade de cada componente do modelo, mais dois testes serão realizados antes da regressão ser propriamente estimada. Um deles é o teste de cointegração. Duas variáveis são cointegradas quando são integradas de mesma ordem e a combinação linear entre as duas é estacionária, mesmo sendo ambas individualmente não estacionárias. É importante lembrar, como deixa claro Enders (2004), que nem todas as variáveis integradas de mesma ordem são cointegradas; e, por outro lado, se elas não forem integradas de mesma ordem, elas não poderão ser cointegradas.

O teste de cointegração a ser usado neste estudo será o de Engle-Granger, que aplica uma variação do teste de raiz unitária explicado acima aos resíduos da equação para verificar a existência de cointegração. Isto é, procura-se avaliar os resíduos são estacionários. Este teste é muito importante nos estudos econométricos, já que auxilia a avaliação das relações de causalidade entre variáveis econômicas. Destaque-se que a direção da causalidade é do passado para o presente, no sentido de que apenas mudanças passadas em uma variável podem afetar o comportamento da outra variável hoje. Os efeitos das expectativas (futuro), por exemplo, não são considerados neste caso.

Para alcançar o principal objetivo proposto por este estudo, irá ser utilizado, após todos os testes explicados acima, o modelo de vetores autorregressivos (VAR). Este modelo foi desenvolvido por Christopher Sims e sua base remete ao teste de causalidade de Granger ${ }^{2}$. O modelo VAR possui um instrumental central de análise conhecido como função impulso-resposta, que verifica a sensibilidade das variáveis econômicas através de simulação de choques específicos em um determinado período. Ou seja, através dessa função, pode-se avaliar como cada variável, a partir da estimação da regressão, responde a um determinado choque advindo de outra variável, ambas presentes na

\footnotetext{
${ }^{2}$ Este teste é muito utilizado nos estudos econométricos, em que pesem suas eventuais limitações, já que auxilia a avaliação das relações de causalidade entre variáveis econômicas e é relativamente simples. Destaque-se que a direção da causalidade é do passado para o presente, no sentido de que apenas mudanças passadas em uma variável podem afetar o comportamento da outra variável hoje. Para detalhes, ver Enders (2004).
} 
mesma regressão. Este instrumento de análise será de suma importância para a investigação proposta por este trabalho.

\subsection{VARIÁVEIS SELECIONADAS E MODELO ECONOMÉTRICO}

Tendo em vista todos os procedimentos econométricos que foram explicados acima e que farão parte do processo de investigação empírica deste estudo, faz-se necessário agora apontar o modelo que será examinado por meio destes procedimentos. Como o objetivo central é analisar o comportamento do IPCA perante os choques e as mudanças que compõem o cenário econômico brasileiro, com vista a avaliar sua capacidade de medir corretamente a inflação, as variáveis usadas no modelo são aquelas consideradas de essencial importância na caracterização da conjuntura econômica na qual o IPCA desenvolve seu papel de balizador do nível de preços.

Em conformidade com a metodologia VAR, a meta principal do referido trabalho será alcançada por meio da estimação do seguinte sistema (1):

$$
\begin{aligned}
& A=\sum_{j=1}^{n} \alpha_{1 j} A_{t-j}+\sum_{j=1}^{n} \beta_{1 j} G_{t-j}+\sum_{j=1}^{n} \gamma_{1 j} N_{t-j}+\sum_{j=1}^{n} \delta_{1 j} A a_{t-j}+\sum_{j=1}^{n} \tau_{1 j} E_{t-j}+\sum_{j=1}^{n} \varphi_{1 j} I_{t-j}+\sum_{j=1}^{n} \omega_{1 j} H_{t-j}+u_{1 t} \\
& G=\sum_{j=1}^{n} \alpha_{2 j} G_{t-j}+\sum_{j=1}^{n} \beta_{1 j} A_{t-j}+\sum_{j=1}^{n} \gamma_{2 j} N_{t-j}+\sum_{j=1}^{n} \delta_{2 j} A a_{t-j}+\sum_{j=1}^{n} \tau_{2 j} E_{t-j}+\sum_{j=1}^{n} \varphi_{2 j} I_{t-j}+\sum_{j=1}^{n} \omega_{2 j} H_{t-j}+u_{2 t} \\
& N=\sum_{j=1}^{n} \alpha_{3 j} N_{t-j}+\sum_{j=1}^{n} \beta_{3 j} A_{t-j}+\sum_{j=1}^{n} \gamma_{3 j} G_{t-j}+\sum_{j=1}^{n} \delta_{3 j} A a_{t-j}+\sum_{j=1}^{n} \tau_{3 j} E_{t-j}+\sum_{j=1}^{n} \varphi_{3 j} I_{t-j}+\sum_{j=1}^{n} \omega_{3 j} H_{t-j}+u_{3 t} \\
& A a=\sum_{j=1}^{n} \alpha_{4 j} A a_{t-j}+\sum_{j=1}^{n} \beta_{4 j} A_{t-j}+\sum_{j=1}^{n} \gamma_{4 j} G_{t-j}+\sum_{j=1}^{n} \delta_{4 j} N_{t-j}+\sum_{j=1}^{n} \tau_{4 j} E_{t-j}+\sum_{j=1}^{n} \varphi_{4 j} I_{t-j}+\sum_{j=1}^{n} \omega_{4 j} H_{t-j}+u_{4 t} \\
& E=\sum_{j=1}^{n} \alpha_{5 j} E_{t-j}+\sum_{j=1}^{n} \beta_{5 j} A_{t-j}+\sum_{j=1}^{n} \gamma_{5 j} G_{t-j}+\sum_{j=1}^{n} \delta_{5 j} N_{t-j}+\sum_{j=1}^{n} \tau_{5 j} A a_{t-j}+\sum_{j=1}^{n} \varphi_{5 j} I_{t-j}+\sum_{j=1}^{n} \omega_{5 j} H_{t-j}+u_{5 t} \\
& I=\sum_{j=1}^{n} \alpha_{6 j} I_{t-j}+\sum_{j=1}^{n} \beta_{6 j} A_{t-j}+\sum_{j=1}^{n} \gamma_{6 j} G_{t-j}+\sum_{j=1}^{n} \delta_{6 j} N_{t-j}+\sum_{j=1}^{n} \tau_{6 j} A a_{t-j}+\sum_{j=1}^{n} \varphi_{6 j} E_{t-j}+\sum_{j=1}^{n} \omega_{6 j} H_{t-j}+u_{6 t} \\
& H=\sum_{j=1}^{n} \alpha_{7 j} H_{t-j}+\sum_{j=1}^{n} \beta_{7 j} A_{t-j}+\sum_{j=1}^{n} \gamma_{7 j} G_{t-j}+\sum_{j=1}^{n} \delta_{7 j} N_{t-j}+\sum_{j=1}^{n} \tau_{7 j} A a_{t-j}+\sum_{j=1}^{n} \varphi_{7 j} E_{t-j}+\sum_{j=1}^{n} \omega_{7 j} I_{t-j}+u_{7 t}
\end{aligned}
$$

Em que $A$ é o IPCA (medido em índice, dez. 1993 = 100), G é o IGP-M (medido em índice, ago. $1994=100)$, $N$ é o núcleo da inflação (\% ao mês, ou a.a. daqui por diante), $A a$ é o IPCA para preços administrados (\% a.m.), $E$ é a taxa de câmbio mensal para compra (R\$/US\$), I é a taxa de juros SELIC (\% a.m.), H é o hiato do produto, os u's são os termos de erro aleatório, $n$ é o número das defasagens necessárias, e $\alpha, \beta, \gamma, \delta, \tau, \varphi, \omega$ Deve-se deixar claro que todas as variáveis têm periodicidade mensal de janeiro de 1999, ano em que foi implementado o regime de metas de inflação, a março de 2010. Todas 
as variáveis, exceto o hiato do produto ${ }^{3}$, foram retiradas da página virtual do Instituto de Pesquisa em Economia Aplicada (IPEA) na seção macroeconomia.

O programa estatístico utilizado para efetuar todos os procedimentos econométricos foi o "Gretl”, um software multiplataforma para análise econométrica livre e de código aberto4.

\subsection{ANÁLISE DOS RESULTADOS}

\section{- Resultados do teste de raiz unitária $(A D F)$ e do teste de cointegração}

Todos os testes ADF foram feitos com constante e com constante e tendência, e também foi utilizada uma opção do programa de fazer o teste para baixo a partir da ordem máxima de defasagem. Assim, foi apontado automaticamente o número correto de defasagens para cada variável. Os resultados obtidos estão sintetizados na tabela abaixo:

Tabela 2 - Resultados do teste ADF

\begin{tabular}{c|c|c|c|c}
\hline Variável & $\begin{array}{c}\mathbf{N}^{\circ} \mathbf{d e} \\
\text { defasagens }\end{array}$ & $\begin{array}{c}\text { P-valor c/ } \\
\text { constante }\end{array}$ & $\begin{array}{c}\text { P-valor c/constante } \\
\text { e tendência }\end{array}$ & Conclusão \\
\hline IPCA índice & 1 & 0,9482 & 0,5512 & variável não estacionária \\
\hline IGP-M índice & 2 & 0,8215 & 0,3339 & variável não estacionária \\
\hline Núcleo da inflação & 4 & 0,009501 & 0,02921 & variável estacionária \\
\hline IPCA preços adm. & 3 & 0,00147 & $5,39 \mathrm{E}-01$ & variável estacionária \\
\hline Taxa de câmbio & 2 & 0,3508 & 0,5478 & variável não estacionária \\
\hline Taxa de juros & 1 & 0,07333 & 0,1914 & variável não estacionária \\
\hline Hiato do produto & 3 & $8,43 \mathrm{E}-10$ & $8,14 \mathrm{E}-09$ & variável estacionária \\
\hline
\end{tabular}

Fonte: Elaboração própria com base nos resultados do teste ADF realizado com o programa GRETL.

Como pode ser notado, as variáveis IPCA índice, IGP-M índice, taxa de câmbio e taxa de juros são não estacionárias. Logo, de acordo com a teoria já explicitada, por serem não estacionárias, elas não podem integrar a mesma regressão, visto que podem dar origem a uma regressão espúria, a menos, como também já foi visto, que elas sejam

\footnotetext{
${ }^{3}$ A variável hiato do produto foi utilizada em substituição ao PIB, já que o trabalho lida com dados mensais e o PIB é calculado trimestralmente. Para obter o hiato do produto, foram utilizados como base os dados referentes à produção industrial da indústria geral (índice de quantum média $2002=100$ ); os mesmos tiveram suas tendências estimadas pelo filtro HP, proposto por Hodrick e Prescott (1997), que é uma das formas mais simples de se obter a tendência de longo prazo como uma média ponderada da série. O filtro HP é calculado a partir da minimização da soma do quadrado das diferenças entre a série efetiva e a tendência de longo prazo, sujeita à restrição de que a soma do quadrado das segundas diferenças da tendência deve ser zero. O peso desta última restrição, representada por " $\lambda$ ”, varia de acordo com a pessoa que esta fazendo o cálculo, e a lógica é que, quanto maior este peso, maior é a tendência que a derivada do filtro HP tem de se aproximar de uma reta. Em contraste, quanto menor o peso atribuído à "suavização" da tendência, mais esta se aproxima da série original. No caso deste trabalho, o peso atribuído à suavização foi de 14.400, já que a intenção era ficar próximo da tendência e também este é um valor-padrão sugerido na literatura sobre o tema para séries mensais, como é o caso da série utilizada por este trabalho. Por fim, com os dados da produção e do filtro HP, foi encontrado o hiato do produto através da seguinte equação: hiato do produto = (produção - filtro HP)/filtro HP.

${ }^{4}$ Para mais informações sobre este software, acessar: < http://gretl.sourceforge.net/gretl_portugues.html>.
} 
cointegradas. Por isso, foi realizado o teste de cointegração de Engle-Granger entre as mesmas e os resultados foram os seguintes:

Tabela 3 - Teste de cointegração de Engle-Granger

\begin{tabular}{c|l}
\hline Variáveis & \multicolumn{1}{c}{ Resultado } \\
\hline IPCA e IGP-M & não são cointegradas \\
\hline IPCA e taxa de câmbio & não são cointegradas \\
\hline IPCA e taxa de juros & não são cointegradas \\
\hline IGP-M e taxa de câmbio & não são cointegradas \\
\hline IGP-M e taxa de juros & não são cointegradas \\
\hline Taxa de juros e taxa de câmbio & não cointegradas \\
\hline IPCA e núcleo da inflação & não cointegradas \\
\hline
\end{tabular}

Fonte: Elaboração própria com base nos resultados do teste de cointegração realizado com o programa GRETL.

De acordo com a tabela, nenhuma das variáveis não estacionárias são cointegradas entre si. Para eliminar a não estacionariedade da taxa de juros e da taxa de câmbio, foi aplicada a primeira diferença em cada uma das variáveis. Já no IPCA e no IGP-M, além da primeira diferença, foi acrescentado logaritmo nas duas variáveis. Dessa forma, após a transformação, trabalhamos aproximadamente com a variação nos índices de preços.

\section{- Resultados do teste de causalidade no sentido de Granger}

Os testes de causalidade foram realizados individualmente para cada par de variáveis. Antes de se realizar cada um, foi verificado o número correto de defasagens a ser usado por cada dupla de variáveis. A seleção foi feita através dos valores obtidos dos critérios de informação (critério de Akaike, Bayesiano de Schwartz e de Hannan-Quinn). Após essa escolha, os pares de variáveis foram estimados por uma autorregressão vetorial e os principais valores obtidos estão sintetizados na tabela que se segue:

Tabela 4 - Testes de causalidade de Granger

\begin{tabular}{|c|c|c|c|c|}
\hline Hipótese nula & $\begin{array}{c}\text { No de } \\
\text { defasagens }\end{array}$ & Estatística F & Probabilidade & Conclusão \\
\hline IGP-M não causa IPCA & 1 & 15,455 & 0,0001 & rejeita \\
\hline IPCA não causa IGP-M & 1 & 0,85324 & 0,3573 & aceita \\
\hline Taxa de câmbio não causa IPCA & 7 & 8,6345 & 0 & rejeita \\
\hline IPCA não causa taxa de câmbio & 7 & 1,6186 & 0,1373 & aceita \\
\hline IPCA administrado não causa o IPCA & 2 & 3,0797 & 0,0494 & rejeita \\
\hline IPCA não causa o IPCA administrado & 2 & 1,1902 & 0,3075 & aceita \\
\hline Núcleo da inflação não causa IPCA & 1 & 6,5297 & 0,0118 & rejeita \\
\hline IPCA não causa núcleo da inflação & 1 & 3,6528 & 0,0582 & aceita \\
\hline Taxa de câmbio não causa IGP-M & 2 & 13,651 & 0 & rejeita \\
\hline IGP-M não causa taxa de câmbio & 2 & 1,1823 & 0,3099 & aceita \\
\hline Taxa de câmbio não causa o IPCA adm. & 2 & 6,0752 & 0,003 & rejeita \\
\hline
\end{tabular}

Fonte: Elaboração própria com base nos resultados do teste de causalidade de Granger realizado com o programa GRETL. 
A significância utilizada para avaliar os resultados obtidos foi de 5\%. Sendo assim, todas as probabilidades inferiores a 5\% indicam a rejeição da hipótese nula, que supõe a inexistência de causalidade entre as variáveis. A análise da hipótese nula também pode ser feita através da estatística $F$.

Observando as conclusões expostas na tabela, pode-se inferir que todas as causalidades apresentadas pelo teste estão em conformidade com a observação da realidade econômica do Brasil, o que permite o seguimento do trabalho com a análise do modelo VAR através das funções impulso-resposta, que irão mostrar as respostas das variáveis a choques levando em conta as causalidades analisadas acima.

-Resultados do modelo VAR: funções impulso-resposta. Análise do IPCA

Uma forma interessante de se começar a investigação é através da observação da reação do IPCA a diferentes choques. O primeiro deles é um choque no índice de preços administrados, como mostra o gráfico:

Gráfico 1 - Resposta do IPCA a um choque no IPCA administrado

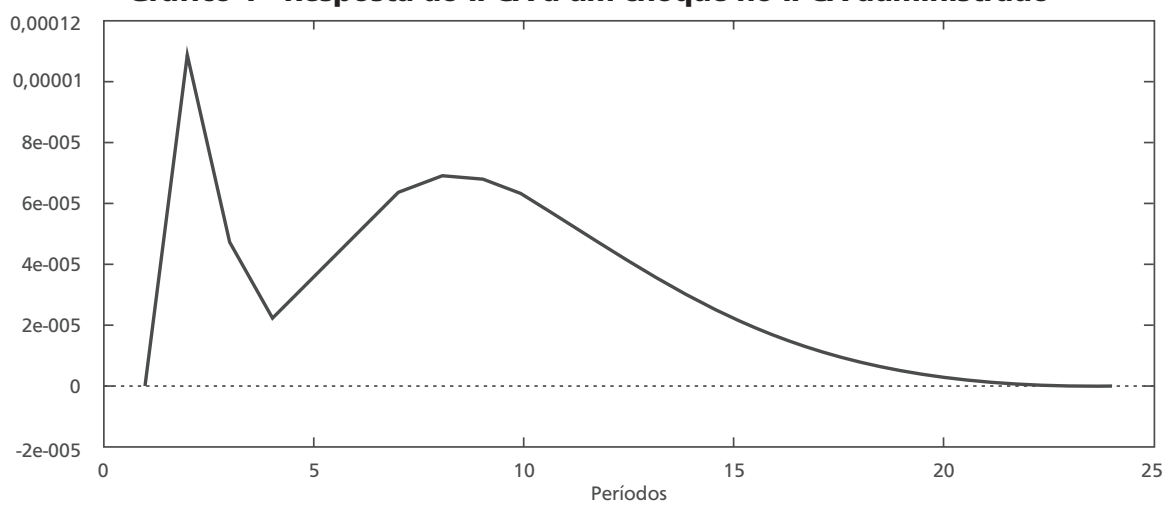

Fonte: Elaboração própria com base na estimação do modelo VAR realizada com o programa GRETL.

Nota-se que, quando o IPCA recebe um choque originado de uma elevação nos preços administrados, ele sofre um primeiro aumento brusco seguido de uma queda e um segundo aumento um pouco menor, mas que persiste por cerca de vinte períodos até o índice voltar ao patamar inicial. Isto comprova a grande e prolongada influência dos preços administrados no IPCA (influência esta já provada pelo teste de causalidade de Granger) e qualifica uma restrição ao mesmo como parâmetro para a inflação brasileira, já que essa parte da inflação devida aos preços administrados não é susceptível a choques na taxa de juros (SELIC), que é o principal instrumento do regime de metas para controlar a inflação. Isto porque, para os preços administrados, a causa da inflação não está relacionada a um excesso de demanda; mas, sim, a outros critérios, inclusive a transmissão de inflação passada. 
Como mostra o gráfico 2, no início, os preços administrados até respondem bem à elevação da taxa de juros; porém, essa primeira reação dura pouco tempo e logo esses preços voltam ao mesmo patamar. Isto prova que, enquanto a inflação do país tiver como medida o IPCA, sempre vai haver uma espécie de componente inercial para a mesma. Além disso, os preços administrados são fortemente influenciados por variações passadas dos Índices Gerais de Preços (IGP) e se mostram muito sensíveis aos preços internacionais do petróleo e a choques na taxa de câmbio, como deixa claro o gráfico 3. Tudo isso acaba obrigando uma redução maior da outra parte da inflação proveniente dos preços livres (determinados pelas condições de oferta e demanda) para que a média da variação desses dois preços fique dentro dos patamares compatíveis com as metas de inflação.

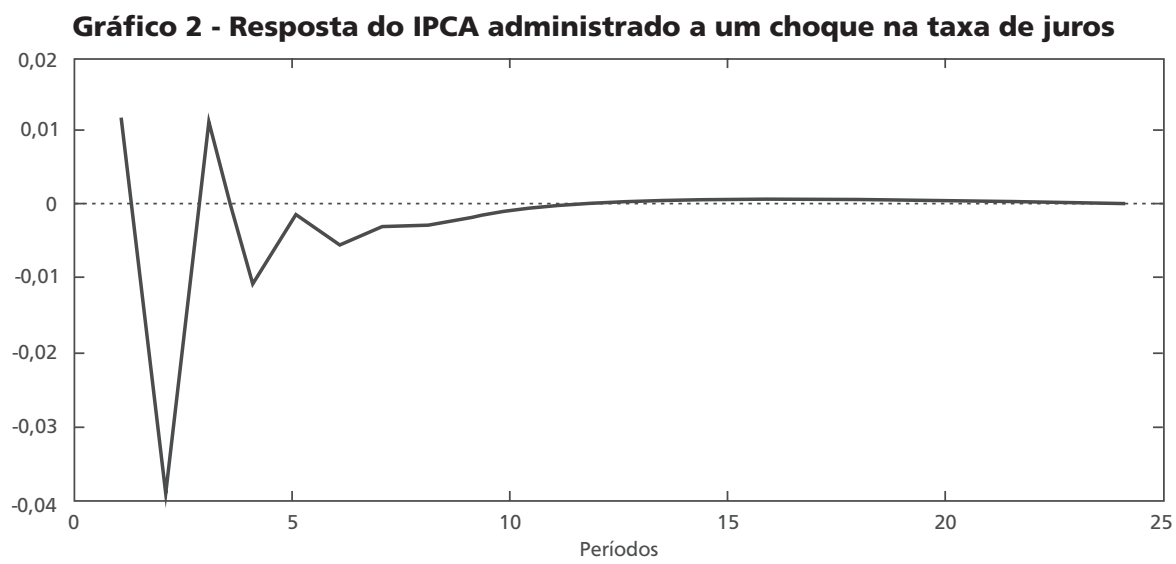

Fonte: Elaboração própria com base nos resultados da estimação do modelo VAR realizada com o programa GRETL.

Gráfico 3 - Resposta do IPCA administrado a um choque no câmbio

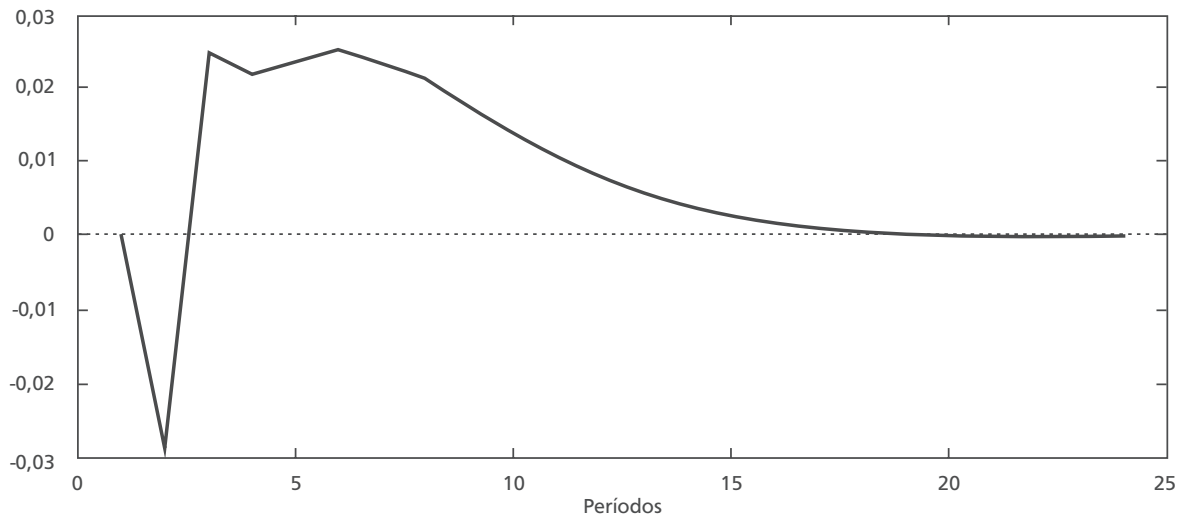

Fonte: Elaboração própria com base nos resultados da estimação do modelo VAR realizada através do programa GRETL. 
Ainda dentro da discussão da participação dos preços administrados no IPCA, o gráfico 4 apresenta mais uma evidência de que tal composição pode fazer com que o índice de preços ao consumidor aqui estudado não responda bem à principal forma de controlar o aumento dos preços utilizado pelo regime de metas. Ele evidencia que o IPCA inicialmente reage com uma queda quando se aplica um choque na taxa de juros; porém, a mesma dura apenas cinco períodos (mesmo assim ainda dura mais tempo do que a reação do IPCA administrado ao mesmo choque). Depois disso, o índice dá início a uma trajetória rumo ao patamar pré-choque. Pelo menos uma parte desta resistência à baixa tem grande possibilidade de ser devido à participação dos preços monitorados, que, como já foi explicitado, não são sensíveis a movimentos na taxa de juros. Tal fato sugere que, para manter a inflação em determinado nível, é necessário aplicar choques constantes na taxa de juros, já que seus efeitos não duram por muito tempo. Ou ainda sugere que esses choques sejam de grande magnitude, como dito anteriormente.

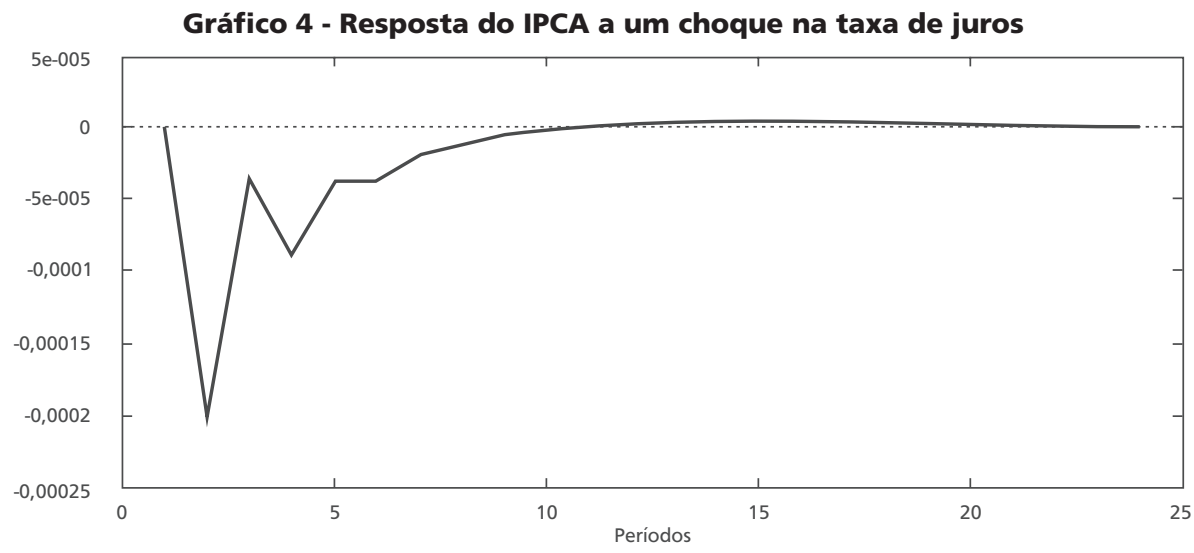

Fonte: Elaboração própria com base nos resultados da estimação do modelo VAR realizada com o programa GRETL.

As constantes altas da taxa de juros que se fazem presentes em nossa economia sempre que é necessário controlar o nível de preços, além não conseguirem controlar toda a inflação apontada pelo IPCA, como sugerido acima, ainda podem causar um custo para o combate inflacionário representado pela redução da taxa de crescimento econômico. Prova disso é o próximo gráfico, que mostra a reação do hiato do produto a um choque na taxa de juros. Observando-o, fica clara a queda brusca do hiato do produto quando acontece o choque; e o impacto é de tamanha magnitude que, apesar da reação não demorar muito para acontecer, ela não é suficiente para que o hiato do produto volte sequer à metade de seu valor anterior ao choque da taxa de juros. 


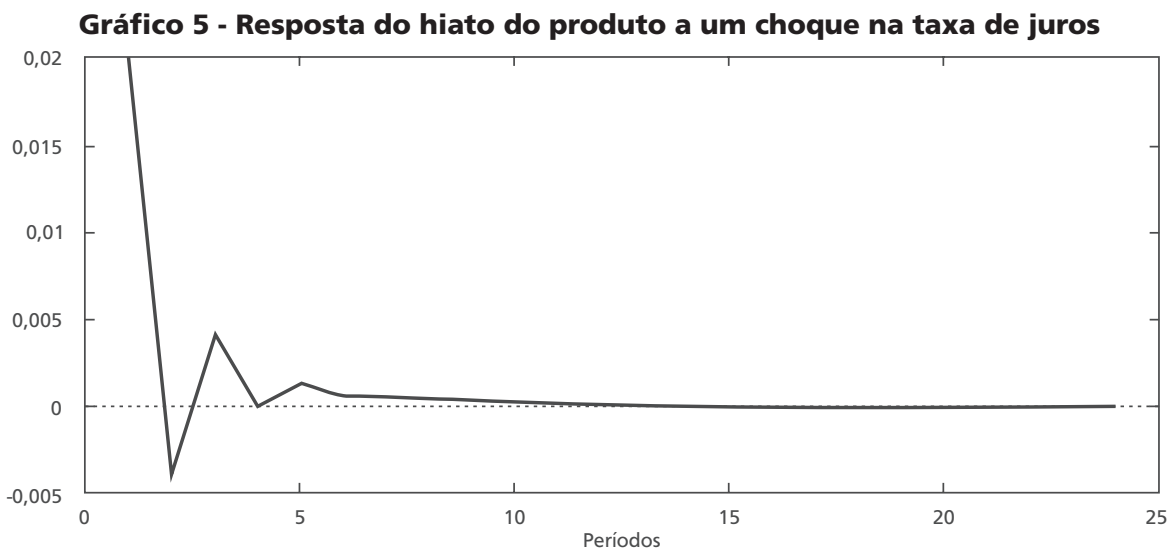

Fonte: Estimação do modelo VAR realizada através do programa GRETL.

Vista toda a análise acima, fica claro que, apesar do regime de metas de inflação conseguir cumprir seu objetivo principal, que é a manutenção do nível da inflação em patamares considerados aceitáveis, isso tem sido feito com um determinado ônus para a economia. Esse custo de se combater a inflação surge porque os preços administrados, que representam 29,5\% do IPCA, apresentam constantemente uma tendência de crescimento maior do que a dos preços livres (como mostra a tabela 1), o que acaba aumentando a parcela da inflação captada pelo IPCA insensível a aumentos na taxa de juros. Sendo assim, os formuladores de política são obrigados a elevar a um nível mais alto os juros (SELIC) para reprimir excessivamente os preços livres, de forma a compensar a forte pressão exercida pelos preços monitorados.

Mantém-se, assim, a SELIC em um nível superior àquele que seria necessário se todos os preços fossem livres. Em consequência dos juros elevados, a demanda agregada é reprimida, o que, por sua vez, acaba gerando redução da taxa de crescimento econômico e um possível aumento da dívida pública, já que a mesma é vinculada à SELIC. (Vale lembrar que toda menção feita ao comportamento da dívida pública neste trabalho é apenas uma possibilidade pautada pelo mecanismo de transmissão da política economia brasileira, já que, para se ter certeza sobre o desempenho de tal dívida, seria necessária uma averiguação empírica da mesma dentro do período aqui estudado.)

Logo, talvez fosse interessante pensar em outro índice ou outra medida para a inflação do país, como, por exemplo, um índice composto por algum núcleo da inflação. Este tipo de medida não leva em conta o efeito de vários preços administrados em sua avaliação da inflação; logo, não seriam necessários juros altos para compensar a elevação desses preços. O núcleo da inflação responde bem melhor a um choque na taxa de juros, demorando um período de tempo maior para voltar ao seu patamar inicial, como mostra o seguinte gráfico: 


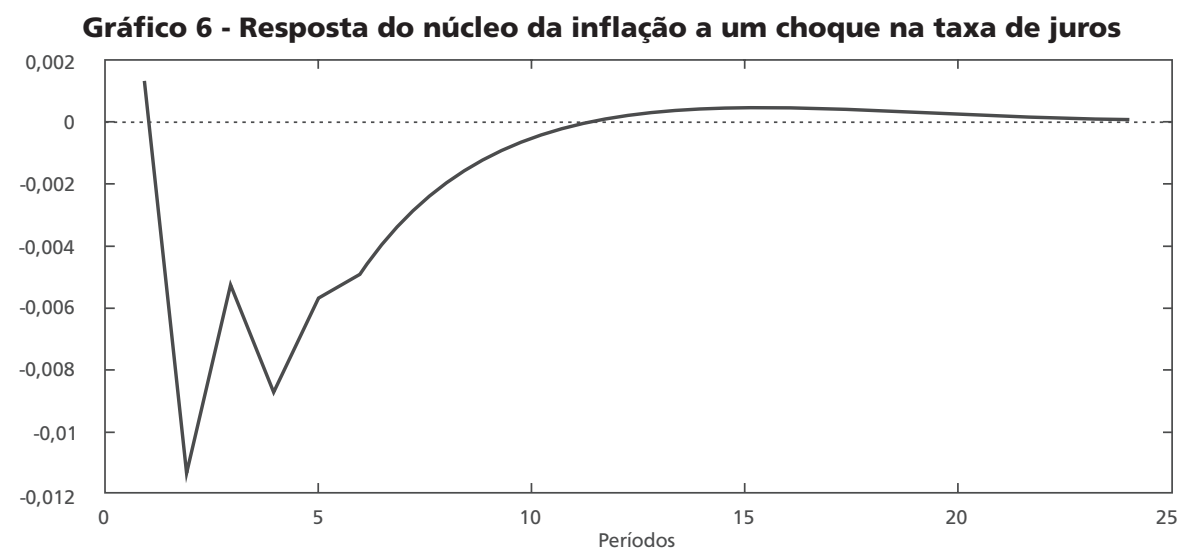

Fonte: Elaboração própria com base nos resultados da estimação do modelo VAR realizada com o programa GRETL.

E, apesar de alguns teóricos defenderem que a adoção do núcleo da inflação pode não ser bem entendida pelos agentes econômicos, hoje em dia, como explica Mendonça (2007), o Brasil já reúne as condições necessárias para a adoção de um núcleo da inflação sem maiores problemas, uma vez que possui: (i) democracia; (ii) transparência na condução da política econômica; e (iii) comprometimento da autoridade monetária do país em assegurar a estabilidade do poder de compra da moeda e a solidez do sistema financeiro nacional.

Com a adoção do núcleo como medida para a inflação, as chances de se alcançar as metas seriam maiores e, assim, haveria um ganho de credibilidade que permitiria uma redução da taxa de juros. E os benefícios dessa mudança seriam fáceis de serem percebidos, já que a pressão para o endividamento público provavelmente seria menor (isso porque, como já foi explicado, a dívida pública brasileira está atrelada à SELIC), sem falar que, com o gasto possivelmente reduzido em relação ao pagamento dos juros, haveria mais recursos disponíveis para serem empregados em outros setores da economia do país.

\section{CONCLUSÃO}

Ao longo de todo este trabalho, tentou-se apresentar os elementos tidos como importantes para o entendimento, análise e crítica, tanto no nível teórico como no empírico, do regime de metas de inflação implantado na economia brasileira.

Os resultados obtidos com os testes empíricos confirmaram que a presença dos preços ajustados por contrato na formação do índice de preços em questão pode ser uma provável explicação para a resistência da inflação brasileira de se manter em patamares 
baixos por longos períodos sem a necessidade de se utilizar de taxas de juros elevadas. Isso porque a inflação produzida por estes preços não respondem bem a aumentos na taxa de juros, que é o principal instrumento de contenção dos preços utilizado pelo regime de metas inflacionárias, sem falar que os mesmos são vulneráveis à variação da taxa de câmbio. Sendo assim, foi proposta uma mudança do balizador da inflação do país, o IPCA, para alguma medida do núcleo da inflação.

Apesar de ter sido indicada por este estudo a veracidade da crítica em relação ao IPCA, não se pode negar que o regime em questão, apesar de suas limitações e do ônus que traz para o desenvolvimento econômico do país, está cumprindo o seu objetivo. Sendo assim, não faz parte do propósito deste trabalho propor outro tipo de conduta para a política monetária brasileira, muito menos julgar determinada teoria como certa ou errada. A intenção foi de apresentar o regime de metas de inflação tal qual ele é, ou seja, com seus mecanismos de funcionamento, suas características e críticas. E, com tudo isso em mente, escolher um de seus pontos controversos, no caso, a utilização do IPCA, fazer uma análise mais aprofundada, e então remeter sugestões de melhoria para o mesmo.

Contudo, o regime monetário de metas de inflação, mesmo fazendo jus ao seu objetivo, ainda precisa ser aperfeiçoado e mais bem adaptado para determinadas características presentes no cenário econômico brasileiro

\section{REFERÊNCIAS}

BANCO CENTRAL DO BRASIL. Índices de preços. Brasília: Gerin, 2003. (Série Perguntas Mais Frequentes)

BANCO CENTRAL DO BRASIL. Preços administrados. Brasília: Gerin, 2010. (Série Perguntas Mais Frequentes)

BANCO CENTRAL DO BRASIL. Relatório de Inflação: Jun. 1999. Relatório de Inflação, Brasília, v. 1, n. 1, p. 1-97, jun., 1999. Disponível em: <http://www.bcb.gov.br/htms/relinf/direita.asp?idio $\mathrm{ma}=\mathrm{P} \& \mathrm{nno}=1999 \&$ acaoAno=ABRIR\&mes=06\&acaoMes=ABRIR $>$. Acesso em: 10 mai. 2010.

BANCO CENTRAL DO BRASIL. Relatório de Inflação: Dez. 2002. Relatório de Inflação, Brasília, v. 4, n. 4, p. 1-188, dez., 2002. Disponível em: <http://www.bcb.gov.br/htms/relinf/direita.asp? idioma $=\mathrm{P} \& a n o=2002 \&$ acaoAno $=\mathrm{ABRIR} \& \mathrm{mes}=12 \&$ acaoMes $=\mathrm{ABRIR}>$. Acesso em: 10 mai. 2010.

BANCO CENTRAL DO BRASIL. Relatório de Inflação: Jun. 2004. Relatório de Inflação, Brasília, v. 6, n. 2, p. 1-157, jun., 2004. Disponível em: <http://www.bcb.gov.br/htms/relinf/ direita.asp idioma $=P \& a n o=2004 \&$ acaoAno $=A B R I R \& m e s=06 \&$ acaoMes $=A B R I R>$. Acesso em: 10 mai. 2010.

BANCO CENTRAL DO BRASIL. Relatório de Inflação: Mar. 2006. Relatório de Inflação, Brasília, v. 8, n. 1, p. 1-165, mar., 2006. Disponível em: <http://www.bcb.gov.br/htms/relinf/ direita.asp idioma $=P \& a n o=2006 \&$ acaoAno $=A B R I R \& m e s=03 \&$ acaoMes $=A B R I R>$. Acesso em: 10 mai. 2010. 
BANCO CENTRAL DO BRASIL. Relatório de Inflação: Mar. 2008. Relatório de Inflação, Brasília, v. 10, n. 1, p. 1-171, mar., 2008. Disponível em: <http://www.bcb.gov.br/htms/relinf/ direita.asp $?$ idioma $=\mathrm{P} \& a n o=2008 \&$ acao $A n o=A B R I R \& m e s=03 \&$ acaoMes $=A B R I R>$. Acesso em: 10 mai. 2010.

BANCO CENTRAL DO BRASIL. Histórico das metas de inflação. Disponível em: <http://www. bcb.gov.br/?SISMETAS>. Acesso em: 20 ago. 2010.

BANCO CENTRAL DO BRASIL. Histórico da taxa de juros (SELIC). Disponível em: <http:// www.bcb.gov.br/?COPOMJUROS>. Acesso em: 21 ago. 2010.

BANCO CENTRAL DO BRASIL. Resolução no 2615 de junho de 1999. Disponível em: $<$ http://www3.bcb.gov.br/normativo/detalharNormativo.do?method=detalharNormativo $\& \mathrm{~N}=099145783>$. Acesso em: 28 jun. 2010.

BANCO CENTRAL DO BRASIL. Sistema especial de liquidação e custódia - SELIC. Disponível em: <http://www.bcb.gov.br/?SPBSELIC>. Acesso em: 24 jun. 2010.

BARRO, R. J.; GORDON, D. B. A positive theory of monetary policy in a natural rate model. Jornal of Political Economy, Chicago, v. 91, n. 3, p. 589-619, 1983.

BRASIL. Decreto n 3.088, de 21 de junho de 1999. Estabelece a sistemática de "metas de inflação" como diretriz para fixação do regime de política monetária e dá outras providências. Diário Oficial da União, Brasília, p. 4. Retificado no DOU, de 23/06/1999, p. 1.

CALVO, G. On the time consistency of optimal policy in the monetary economy. Econometrica, v. 46, n. 4 , p. $1.411-1.428,1978$.

CARVALHO, F. J. C.; SOUZA, F. E. P.; SICSÚ, J.; PAULA, L. F. R.; STUDART, R. Economia monetária e financeira. Rio de Janeiro: Elsevier Campus, 2007.

CARVALHO, F. J. C. Economic policies for monetary economies. Revista de Economia Política, v. 17, n. 4 (68), p. 31-51, out./nov., 1997.

CURADO, M. L.; OREIRO, J. L. Metas de inflação: uma avaliação do caso brasileiro. Texto para discussão, CDME/UFPR, n. 15, 2005.

CUKIERMAN, A., WEBB, S. B. E NEYAPT, B. Measuring central bank independence and its effect on policy outcomes. San Francisco: ISS PRESS, 1994

ENDERS, W. Applied econometric time series. 2. ed. New York: Wiley, 2004.

FARHI, M. Metas de inflação e o medo de crescer. Política Econômica em Foco, Campinas, n. 4, seção III, p. 73-91, mai./out., 2004.

FERRARI FILHO, F. O legado do Plano Real: uma estabilização sem crescimento econômico? Revista Análise Econômica, Porto Alegre, n. 35, p. 5-21, mar., 2001.

FERREIRA, A. B. Metas para a inflação e vulnerabilidade externa: um estudo do Brasil. Dissertação de Mestrado em Economia, Centro de Desenvolvimento e Planejamento Regional, Faculdade de Ciências Econômicas, Universidade Federal de Minas Gerais, Belo Horizonte, 2004.

FIANI, R. Teoria dos jogos. Rio de Janeiro: Campus, 2006.

FIGUEIREDO, F. M. R.; FERREIRA, T. P. Os preços administrados e a inflação no Brasil. Working Paper, Banco Central do Brasil, Brasília, n. 59, p. 3-25, dez., 2002. Disponível em:<http:// www.bcb.gov.br/pec/wps/port/wps59>. Acesso em: 25 jun. 2010. 
FILGUEIRAS, L. A. M. História do Plano Real: Fundamentos, impactos e contradições. São Paulo: Boitempo, 2006.

FRAGA, A.; GOLDFAJN, I.; MINELLA, A. Inflation targeting in emerging market economies. Working Paper, Banco Central do Brasil, Brasília, n. 76, p. 1-49, jun., 2003.

FRANCO, G. O Plano Real e outros ensaios. Rio de Janeiro: Francisco Alves, 1995.

FRIEDMAN, M. “Should there be an independent monetary authority?” In: LEUBE, K. R. (Ed.) The Essence of Friedman. Stanford: Hoover Institution Press, 1987.

GOMES, C.; AIDAR, O. Metas inflacionárias, preços livres e administrados no Brasil: Uma análise econométrica. In: Encontro Nacional de Economia, 23, João Pessoa, PB, 7-10 dez. 2004. Anais. São Paulo: ANPEC, 2004, p. 1-17. Disponível em: <http://www.anpec.org.br/encontro2004/artigos/A04A031.pdf >. Acesso em: 26 set. 2010.

GOODHART, C. Central Bank independence. FMG Special Paper, Financial Market Group of the London School of Economy, n. 57, Nov., 1993. Disponível em: <http://fmg.lse.ac.uk/publication/pdfs/sp0057.pdf>. Acesso em: 03 ago. 2010.

GUJARATI, D. N. Econometria básica. 3. ed. Rio de Janeiro: Elsevier,Campus, 2006.

HODRICK, R. J., PRESCOTT, E. C. Postwar U.S. business cycles: an empirical investigation. Journal of Money, Credit and Banking, v. 29, n. 1, p. 1-16, 1997.

INSTITURO BRASILEIRO DE GEOGRAFIA E ESTATÍSTICA-IBGE. Nova série de contas nacionais. Disponível em:<http://www.ibge.gov.br/home/presidencia/noticias $>$. Acesso em: 03 out. 2010.

INSTITUTO DE PESQUISA EM ECONOMIA APLICADA-IPEA. Macroeconômico. Séries históricas. Rio de Janeiro: IPEA. Disponível em: <http://www.ipeadata.gov.br/ipeaweb.dll/ ipeadata?1558270312>. Acesso em: 19 out. 2010.

KYDLAND, F.; PRESCOTT, E.C. Rules rather than discretion: The inconsistency of optimals plans. Journal of Political Economy, v. 85, n. 3, p. 473-492, 1977.

MINELLA, A., FREITAS, P. S., GOLDFAJN, I. E MUINHOZ, M. K. Inflation targeting in Brazil: constructing credibility under exchange rate volatility. Working Paper, Banco Central do Brasil, Brasília, n. 77, p. 1-38, jul., 2003. Disponível em: <http://www.bcb.gov.br/ingles/ publicwps/wps77.pdf>. Acesso em: 22 jun. 2010.

MENDONÇA, H. F. Mensurando a credibilidade do regime de metas inflacionárias no Brasil. Revista Economia e Política, São Paulo, v. 24, n. 3, jul./set., 2004.

MENDONÇA, H. F. Metas para inflação e taxa de juros no Brasil: uma análise do efeito dos preços livres e administrados. Revista de Economia Política, v. 27, n. 3 (107), p. 431-451, jul./set., 2007.

MINISTÉRIO DA FAZENDA. Conselho Monetário Nacional-CMN. Disponível em: <http://www. fazenda.gov.br/portugues/orgaos/cmn/cmn.asp>. Acesso em: 10 jun. 2010.

MODENESI, A. M. Regimes monetários: teoria e experiência do Real. Rio de Janeiro: Manole, 2005.

MUTH, J. Rational expectations and the theory of price movements. Econometrica, v. 29, n. 3, p. 315-336, jul., 1961.

NETTO, A. D. Sobre as metas inflacionárias. Revista de Economia Aplicada, São Paulo, v. 3, n. 3, p. 357-382, 1999.

PLOSSER, C. I. Understanding real business cycles. Journal of Economic Perspectives, v. 3, n. 3, p. 51-77, 1989. 
RIBEIRO, J. R.; ALMEIDA, L. T. de; PRESSER, M. F. O comportamento dos principais índices de preços da economia brasileira no período 1999-2005: Evidências da impropriedade do IGP como medida síntese da inflação nacional. In: Encontro Nacional de Economia Política, 12, São Paulo, 05-08 jun., 2007.

ROGOFF, K. The optimal degree of commitment to an intermediate monetary target. The Quarterly Journal of Economics, Cambridge, v. 100, n. 4, p. 1169-89, nov., 1985.

SATORIS, A. Estatística e introdução à econometria. São Paulo: Saraiva, 2003.

SIMS, C. A. Macroeconomics and reality. Econometrica, v. 48, n. 1, p. 1-48, jan., 1980.

SICSÚ, J. A tese da independência do Banco Central e a estabilidade de preços: uma aplicação do método Cukierman à história do FED. Estudos Econômicos. São Paulo, v. 26, n. 1, p. 2149, 1996.

SICSÚ, J. Teoria e evidências do regime de metas inflacionárias. Revista Economia e Política. Rio de Janeiro, v. 22, n. 1 (85), jan./mar., 2002.

SILVA, M. L. F. Plano Real e âncora cambial. Revista de Economia Política, v. 22, n. 3 (87), p. 3-24, jul./set., 2002.

STOCK, J. H.; WATSON, M. W. Econometria. São Paulo: Addison Wesley, 2004.

TRUMAN, E. M. Inflation targeting and the international financial system: challenges and opportunities. Washington, DC: Institute for International Economics, 2003.

WALSH, C. E. Optimal contracts for central bankers. The American Economic Review, Boston, v. 85, n. 1, p. 150-167, mar., 1995.

WOOLDRIDGE, J. M. Introdução à econometria: uma abordagem moderna. São Paulo: Cengage Learning, 2006. 